\title{
Resposta de Diferentes Populações de Digitaria insularis ao HERBICIDA GLYPHOSATE ${ }^{1}$
}

\author{
Response of Different Digitaria insularis Populations to Glyphosate
}

\author{
CORREIA, N.M. ${ }^{2}$, LEITE, G.J. ${ }^{3}$ e GARCIA, L.D. ${ }^{4}$
}

\begin{abstract}
RESUMO - Objetivou-se com estse trabalho avaliar o controle quimico de diferentes populações de capim-amargoso (Digitaria insularis) pelo herbicida glyphosate por meio de curva de dose-resposta, além de propor tratamentos alternativos para as populações mais tolerantes. O delineamento experimental foi o de blocos ao acaso, com quatro repetições, em esquema fatorial $5 \times 9$. As sementes de capim-amargoso foram coletadas em cinco locais: área de produção de grãos da Fazenda de Ensino, Pesquisa e Produção da UNESP, Jaboticabal (SP); área de produção comercial de grãos, localizada nos municípios de Campo Florido-MG e Rio Verde-GO; pomar de laranja, localizado no município de Matão (SP); e área não agrícola sem histórico da aplicação de glyphosate (Jaboticabal-SP). O glyphosate (OD, 1/4D, 1/2D, D, 2D, 4D e 8D, em que D é a dose recomendada de $1,5 \mathrm{~kg} \mathrm{ha}^{-1}$ de equivalente ácido) e as suas associações [glyphosate + fluazifop-p-butil $\left(1,5+0,25 \mathrm{~kg} \mathrm{ha}^{-1}\right)$ e glyphosate $\left(1,5 \mathrm{~kg} \mathrm{ha}^{-1}\right) \mathrm{com}$ sequencial de diuron + paraquat $\left(0,20+0,40 \mathrm{~kg} \mathrm{ha}^{-1}+0,2 \%\right.$ de surfatante)] foram pulverizados em plantas de sete a oito perfilhos e altura média de $20 \mathrm{~cm}$. As populações de capim-amargoso de Campo Florido e Rio Verde foram consideradas suscetiveis; as de Jaboticabal e Matão, tolerantes; e a da área não agrícola, de sensibilidade intermediária. A associação de glyphosate ao fluazifop ou a sua aplicação com sequencial de diuron + paraquat foram eficazes no controle das populações mais tolerantes de capim-amargoso.
\end{abstract}

Palavras-chave: capim-amargoso, controle químico, dessecação, tolerância.

\begin{abstract}
The objective of this study was to evaluate the chemical control of different sourgrass (Digitaria insularis) populations by the herbicide glyphosate through dose-response curves, besides considering alternative treatments to control tolerant populations. A randomized block design was used with four replications, in a factorial scheme $(5 x$ 9). Sourgrass seeds were colleted from five locations: a grain production area located at the educational, research and production farm of UNESP, Jaboticabal-SP; a grain production area located in the agricultural area of Campo Florido, $M G$, and Rio Verde, GO; citrus production area located in the agricultural area of Matão, $S P$, and an area without previous glyphosate application (Jaboticabal-SP). Glyphosate (OD, 1/4D, 1/2D, D, 2D, $4 D$ and $8 D$, where $D$ is the recommended rate of $1.5 \mathrm{~kg} \mathrm{ha}{ }^{-1}$ of acid equivalent) and its associations Iglyphosate plus fluazifop-p-butyl (1.5 plus $\left.0.25 \mathrm{~kg} \mathrm{ha}^{-1}\right)$ and glyphosate $\left(1.5 \mathrm{~kg} \mathrm{ha} \mathrm{F}^{-1}\right)$ in sequence with diuron plus paraquat $(0.20$ plus $0.40 \mathrm{~kg}$ ha-1 plus $0.2 \%$ of surfactant)] were sprayed on the 7-8 tiller plants with average height of $20 \mathrm{~cm}$. Campo Florido, MG and Rio Verde, GO sourgrass populations were considered susceptible; those of Jaboticabal-SP and Matão, SP were found to be tolerant and those from the nonagricultural area were considered of intermediate sensitivity. The association of glyphosate with fluazifop, or its application in sequence with diuron plus paraquat, were efficient in the control of sourgrass tolerant populations.
\end{abstract}

Keywords: chemical control, sourgrass, desiccation, tolerant

1 Recebido para publicação em 16.11.2009 e na forma revisada em 12.11.2010.

2 Prof., Dr., Dep. de Fitossanidade, Universidade Estadual Paulista - UNESP, Campus de Jaboticabal-SP, Via de Acesso Prof. Paulo Donato Castellane, s/n., 14.884-900 Jaboticabal-SP, Brasil, <correianm@fcav.unesp.br>; ${ }^{3}$ Técnico Agrícola, Dep. de Fitossanidade, UNESP, Campus de Jaboticabal-SP, ${ }^{4}$ Engo-Agr ${ }^{\circ}$., Syngenta Proteção de Cultivos Ltda., Jaboticabal-SP, Brasil. 


\section{INTRODUÇÃO}

Nas áreas agrícolas onde não há o estabelecimento de culturas de cobertura na entressafra, tem-se observado aumento na infestação de capim-amargoso (Digitaria insularis). Trata-se de uma espécie perene, herbácea, ereta, de colmos estriados e com 50 a $100 \mathrm{~cm}$ de altura. Forma touceiras a partir de curtos rizomas e se reproduz por semente. Possui grande potencial como invasora, pois suas sementes, revestidas por muitos pelos, são carregadas pelo vento a grandes distâncias, tendo bom poder germinativo (Kissmann $\&$ Groth, 1997).

No início do crescimento vegetativo, principalmente quando em condições de sombreamento ou de baixas temperaturas, as plantas de capim-amargoso podem ser suprimidas pelo desenvolvimento mais rápido de outras espécies da comunidade infestante (Machado et al., 2006). Isso ocorre devido ao seu crescimento inicial lento até os 45 dias. No entanto, se a dose do herbicida não for suficiente para controlá-la, essa espécie pode se tornar dominante, como ocorre em muitos casos em áreas de café, citros e plantio direto, em que a dose de glyphosate é eficaz para outras espécies e insatisfatória para o adequado controle de capim-amargoso (Machado et al., 2006).

Por meio de curva de dose-resposta, Lacerda \& Victória Filho (2004) verificaram suscetibilidade intermediária de capimamargoso ao glyphosate, com redução expressiva de crescimento na dose de $1,44 \mathrm{~kg} \mathrm{ha}^{-1}$. Nesse trabalho, as aplicações foram realizadas em plântulas com apenas quatro folhas, antes do seu perfilhamento. Em observações no campo, em áreas onde há o uso contínuo de glyphosate, constata-se que plantas originárias de sementes, quando jovens, são controladas pelo herbicida. Contudo, quando elas se desenvolvem e formam rizomas, seu controle é ineficaz (Machado et al., 2006). A reserva de amido acumulada nos rizomas pode ser responsável pela tolerância do capim-amargoso ao glyphosate, dificultando a translocação e permitindo rápida rebrota da parte aérea após ser tratada com o herbicida (Machado et al., 2008). Portanto, o melhor período para controle dessa espécie seria até os 35 dias após a emergência, quando os rizomas ainda não foram formados (Machado et al., 2006).

Apesar da dificuldade do controle químico de plantas adultas de capim-amargoso, obtêmse resultados satisfatórios utilizando-se doses mais elevadas de glyphosate ou a sua associação com outros herbicidas (Procópio et al., 2006a). No entanto, em algumas áreas agrícolas do Centro-Sul brasileiro as populações adultas dessa espécie têm exigido doses ainda maiores, sem sucesso no controle (Correia \& Durigan, 2009). Em Jaboticabal (SP), estes autores relataram que a aplicação de $2,88 \mathrm{~kg}$ e.a. ha ${ }^{-1}$ de glyphosate não foi eficaz no controle de capim-amargoso. Apesar do controle inicial, $70 \%$ das plantas rebrotaram, comprovando a capacidade de recuperação delas.

Com base nos problemas observados em campo sobre a dificuldade e a resposta diferencial do controle químico de capim-amargoso, tanto em áreas de plantio direto como em pomares de citros, objetivou-se avaliar o controle químico de diferentes populações de capim-amargoso ( $D$. insularis) pelo herbicida glyphosate por meio de curva de dose-resposta, além de propor tratamentos alternativos para as populações tolerantes.

\section{MATERIAL E MÉTODOS}

O experimento foi desenvolvido em vasos mantidos em condições ambientes, durante os meses de novembro de 2008 a março de 2009, no Departamento de Fitossanidade da UNESP, campus de Jaboticabal-SP.

O delineamento experimental foi o de blocos ao acaso, com quatro repetições, em esquema fatorial $5 \times 9$. Foram avaliadas cinco populações de capim-amargoso, sete doses de glyphosate (OD, 1/4D, 1/2D, D, 2D, 4D e 8D, em que $D$ é a dose recomendada de $1,5 \mathrm{~kg} \mathrm{ha}^{-1}$ de equivalente ácido), além de duas associações de herbicidas ao glyphosate [glyphosate + fluazifop-p-butil $\left(1,5+0,25 \mathrm{~kg} \mathrm{ha}^{-1}\right) \mathrm{e}$ glyphosate $\left(1,5 \mathrm{~kg} \mathrm{ha}^{-1}\right)$ com sequencial de diuron + paraquat $\left(0,20+0,40 \mathrm{~kg} \mathrm{ha}^{-1}+0,2 \%\right.$ de surfatante)].

Entre a última semana do mês de setembro e a primeira de outubro de 2008, as sementes de capim-amargoso foram coletadas em 
cinco locais: área de produção de grãos da Fazenda de Ensino, Pesquisa e Produção da UNESP, Jaboticabal-SP; área de produção comercial de grãos, localizada nos municipios de Campo Florido-MG e Rio Verde-GO; pomar de laranja, localizado no município de Matão$\mathrm{SP}$; e área não agrícola sem histórico da aplicação de glyphosate (Jaboticabal-SP).

Na segunda quinzena do mês de novembro de 2008, as sementes de capim-amargoso foram semeadas em bandejas de isopor, para a formação de mudas. Quando as plântulas apresentavam de duas a três folhas totalmente expandidas, foi feito o transplante para os vasos, com posterior desbaste, mantendose três plantas por vaso. Vinte e sete dias após o transplante, as plantas receberam adubação de cobertura com $\mathrm{N}$ e K. Adicionou-se, por vaso, $0,80 \mathrm{~g}$ de $\mathrm{N}$ (sulfato de amônio) e 1,24 g de $\mathrm{K}$ (cloreto de potássio). A irrigação foi realizada com o propósito de manter a capacidade de campo do solo próxima a $75 \%$.

Cada unidade experimental foi constituída por um vaso plástico com capacidade para oito litros, preenchido com a mistura de terra, areia e esterco, na proporção de $3: 1: 0,5$, respectivamente. $O$ solo de textura argilosa foi coletado na camada de $0-20 \mathrm{~cm}$ do perfil do solo e peneirado em malha de $5 \mathrm{~mm}$.

Os tratamentos de herbicidas foram aplicados com o auxílio de pulverizador costal, a pressão constante (mantida por $\mathrm{CO}_{2}$ comprimido) de 2,8 $\mathrm{kgf} \mathrm{cm}^{-2}$, munido de barra com duas pontas de pulverização XR 110015 , espaçadas de $0,5 \mathrm{~m}$, com consumo de calda equivalente a $150 \mathrm{~L} \mathrm{ha}^{-1}$. As plantas apresentavam de sete a oito perfilhos, altura média de $20 \mathrm{~cm}$ e acúmulo de $40 \mathrm{~g}$ de matéria seca total. Para a realização da avaliação destrutiva, foram mantidos quatro vasos adicionais para cada população. No tratamento de glyphosate $\left(1,5 \mathrm{~kg} \mathrm{ha}^{-1}\right)$ combinado a diuron + paraquat $\left(0,20+0,40 \mathrm{~kg} \mathrm{ha}^{-1}+0,2 \%\right.$ de surfatante $)$, a aplicação sequencial de diuron + paraquat foi feita 14 dias após a primeira. Os valores da temperatura do ar e do solo, da umidade relativa do ar e da velocidade do vento registrados no momento das duas pulverizações estão apresentados na Tabela 1.

Aos 28 e 56 dias após a aplicação (DAA) dos herbicidas, foram realizadas avaliações visuais de controle, utilizando-se escala de notas de 0 a $100 \%$, em que zero representa a ausência de injúrias visuais e 100 a morte da planta. Aos 56 DAA, foi realizada a coleta de toda a parte aérea verde das plantas. As plantas totalmente secas ( $100 \%$ de controle) ou as folhas e as hastes secas das plantas controladas parcialmente não foram coletadas. $\mathrm{O}$ material foi levado para secagem em estufa a $50{ }^{\circ} \mathrm{C}$, até atingir massa constante, quando foi avaliado.

Para fins de análise estatística, os nove tratamentos de herbicidas foram desdobrados em dois grupos (Tabela 2). No primeiro, os dados foram analisados utilizando-se curvas de dose-resposta e, no segundo, as médias dos tratamentos de interesse foram comparadas pelo teste de Tukey a 5\% de probabilidade. Para cada conjunto de tratamentos, os resultados obtidos foram submetidos à análise de variância, empregando-se o teste F.

Para a análise por meio de curvas de doseresposta, os dados foram ajustados à equação sigmoidal de Boltzmann:

$$
y=A_{2}+\left(\mathrm{i}_{1}-A_{2}\right) /\left(1+\exp \left(\left(\mathrm{x}-\mathrm{C}_{50}\left(\text { ou } \mathrm{GR}_{50}\right)\right) / d x\right)\right)
$$

em que o parâmetro $A_{2}$ representa a maior dose onde não houve fitointoxicação ou redução de

Tabela 1 - Temperaturas do ar e do solo, umidade relativa do ar e velocidade do vento no início e término das aplicações dos herbicidas, além das datas e horários das pulverizações. Jaboticabal-SP. 2008/2009

\begin{tabular}{|c|c|c|c|c|c|c|}
\hline \multirow{2}{*}{ Aplicação } & \multirow{2}{*}{ Data } & \multirow{2}{*}{ Horário } & \multicolumn{2}{|c|}{ Temperatura $\left({ }^{\circ} \mathrm{C}\right)$} & \multirow{2}{*}{$\begin{array}{l}\text { Umidade do ar } \\
\qquad\left({ }^{\circ} \mathrm{C}\right)\end{array}$} & \multirow{2}{*}{$\begin{array}{c}\text { Vento } \\
\left(\mathrm{km} \mathrm{h}^{-1}\right)\end{array}$} \\
\hline & & & $\mathrm{Ar}$ & Solo & & \\
\hline Primeira & $14 / 01 / 2009$ & $10: 10-11: 08$ & $28,0-30,9$ & $31,8-31,9$ & $76-73$ & $2-3$ \\
\hline Segunda ${ }^{1 /}$ & $28 / 01 / 2009$ & $14: 10$ & $29,2-29,5$ & $28,4-28,7$ & $74-70$ & Zero \\
\hline
\end{tabular}

${ }_{1 /}$ Aplicação de diuron + paraquat 14 dias após a primeira no tratamento glyphosate $\left(3,0 \mathrm{~L} \mathrm{ha}^{1}\right)$ com sequencial de diuron + paraquat $(0,2$ $+0,4 \mathrm{~kg} \mathrm{ha}^{-1}+0,2 \%$ de surfatante). 
Tabela 2 - Local das populações de capim-amargoso (Digitaria insularis), produto comercial, ingrediente ativo e doses avaliadas no experimento, agrupados em função das análises estatísticas (qualitativa e quantitativa) realizadas. Jaboticabal-SP. $2008 / 2009$

\begin{tabular}{|c|c|c|c|c|}
\hline \multirow[b]{2}{*}{ Local das populações } & \multicolumn{2}{|c|}{ Herbicida } & \multicolumn{2}{|c|}{ Dose } \\
\hline & Produto comercial & Ingrediente ativo & $\begin{array}{l}\text { Ingrediente ativo } \\
\qquad\left(\mathrm{kg} \mathrm{h}^{-1}\right)\end{array}$ & $\begin{array}{l}\text { Produto comercial } \\
\qquad\left(\mathrm{L} \mathrm{ha}^{-1}\right)\end{array}$ \\
\hline \multirow{6}{*}{ Campo Florido } & \multicolumn{4}{|c|}{ Análise quantitativa (curva de dose-resposta) } \\
\hline & 01-glyphosate & Zapp QI & 0,0 & 0,0 \\
\hline & 02-glyphosate & Zapp QI & 0,375 & 0,75 \\
\hline & 03-glyphosate & Zapp QI & 0,75 & 1,5 \\
\hline & 04- glyphosate & Zapp QI & 1,5 & 3,0 \\
\hline & 05-glyphosate & Zapp QI & 3,0 & 6,0 \\
\hline \multirow[t]{2}{*}{ Matão } & 06- glyphosate & Zapp QI & 6,0 & 12,0 \\
\hline & 07-glyphosate & Zapp QI & 12,0 & 24,0 \\
\hline Rio Verde & \multicolumn{4}{|c|}{ Análise qualitativa (teste de média) } \\
\hline \multirow{4}{*}{$\begin{array}{l}\text { Área sem histórico de } \\
\text { aplicação }\end{array}$} & 01 - glyphosate & Zapp QI & 0,0 & 0,0 \\
\hline & 02- glyphosate & Zapp QI & 1,5 & 3,0 \\
\hline & 03- glyphosate fluazifop-p-butil & $\begin{array}{l}\text { Zapp QI } \\
\text { Fusilade 250 EW } \\
\end{array}$ & $1,5+0,25$ & $3,0+1,0$ \\
\hline & 04- glyphosate paraquat + diuron & Zapp QI Gramocill ${ }^{1 /}$ & $1,5+0,4+0,2$ & $3,0+2,0$ \\
\hline
\end{tabular}

$\underline{1} /$ Foi adicionado de Agral $(0,2 \%)$.

matéria seca; $A_{1}$, a menor dose causadora de danos absolutos; $d x$, a declividade; $\mathrm{e}_{50}$ ou $\mathrm{GR}_{50}$, a dose de glyphosate necessária para causar $50 \%$ de injúrias nas plantas (adaptado de Seefeldt et al., 1995; Lamego \& Vidal, 2008). $\mathrm{O} \mathrm{C}_{50}$ ou $\mathrm{GR}_{50}$ são as doses do herbicida que proporcionam $50 \%$ de controle ou de redução de matéria seca da planta daninha, respectivamente (Christoffoleti \& López-Ovejero, 2008). Nessa análise, a matéria seca foi corrigida para valores percentuais, por meio da comparação da massa obtida nas doses crescentes de glyphosate com a massa da testemunha $\left(0,0 \mathrm{~kg} \mathrm{ha}^{-1}\right.$ de glyphosate), considerada $100 \%$

\section{RESULTADOS E DISCUSSÃO}

A interação populações $\mathrm{x}$ doses de glyphosate foi significativa $(p<0,01)$ para todas as variáveis avaliadas. Procedendo-se ao desdobramento da interação, os dados de controle e de matéria seca de cada população estudada foram ajustados às curvas sigmoidais de Boltzmann. Para todas as populações, as curvas de resposta às doses de glyphosate indicaram que o nivel de controle aumentou com o comportamento sigmoidal em função do aumento das doses do herbicida (Figuras 1, 2 e 3). Para as populações de Campo Florido e Rio Verde, o incremento no nivel de controle ou da redução de matéria seca ocorreu em menor dose e com maior intensidade do que nas demais populações.

Aos 28 DAA, as doses de glyphosate necessárias para promover $50 \%$ de controle $\left(\mathrm{C}_{50}\right)$

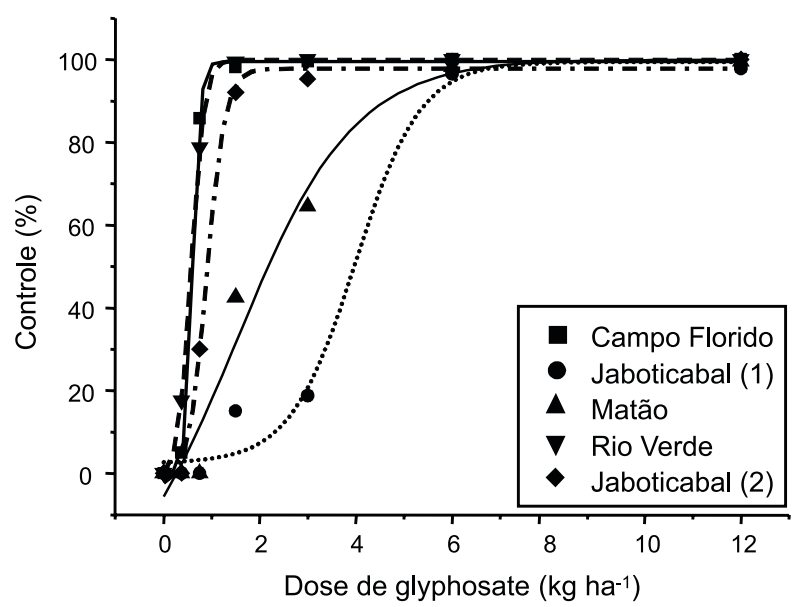

Figura 1 - Controle (\%) de cinco populações de capim-amargoso (Digitaria insularis) aos 28 dias após a aplicação (DAA) de diferentes doses de glyphosate. Jaboticabal (1): área de produção de grãos; e Jaboticabal (2): área não agrícola. Jaboticabal-SP. 2008/2009. 
de capim-amargoso foram de 0,570; 0,605; 0,$895 ; 1,514 ;$ e $3,988 \mathrm{~kg} \mathrm{ha}^{-1}$ para os individuos de Rio Verde, Campo Florido, área não agrícola de Jaboticabal [Jaboticabal (2)], Matão e área de produção de grãos de Jaboticabal [Jaboticabal (1)], respectivamente (Tabela 3 ). No estudo sobre a resposta de 21 acessos de Amaranthus palmeri a oito doses de glyphosate $(17,5 ; 35 ; 70$;

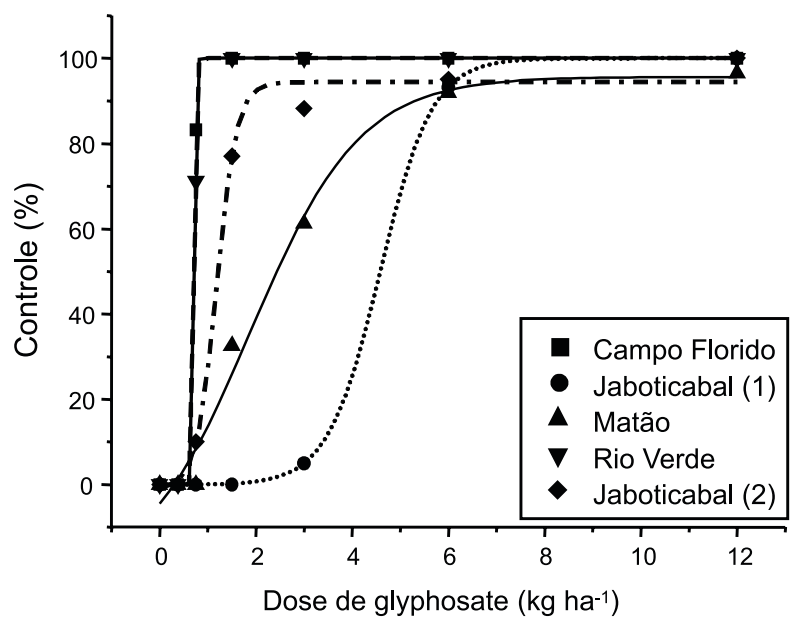

Figura 2 - Controle (\%) de cinco populações de capim-amargoso (Digitaria insularis) aos 56 dias após a aplicação (DAA) de diferentes doses de glyphosate. Jaboticabal (1): área de produção de grãos; e Jaboticabal (2): área não agrícola. Jaboticabal-SP. 2008/2009.
140; 280; 560; $1.120 ;$ e 2.240 g e.a. ha ${ }^{-1}$ ) quando pulverizado em plantas de 7 a $10 \mathrm{~cm}$ de altura, Norsworthy et al. (2008) relataram que o acesso AR10 teve menor $\mathrm{C}_{50}$, ou seja, apenas $41 \mathrm{~g} \mathrm{ha}^{-1}$ de glyphosate foi suficiente para o controle de $50 \%$ das plantas desse acesso; e o AR18 e o AR19 foram os menos sensiveis, com $\mathrm{C}_{50}$ de 312 e $339 \mathrm{~g} \mathrm{ha}^{-1}$, respectivamente.

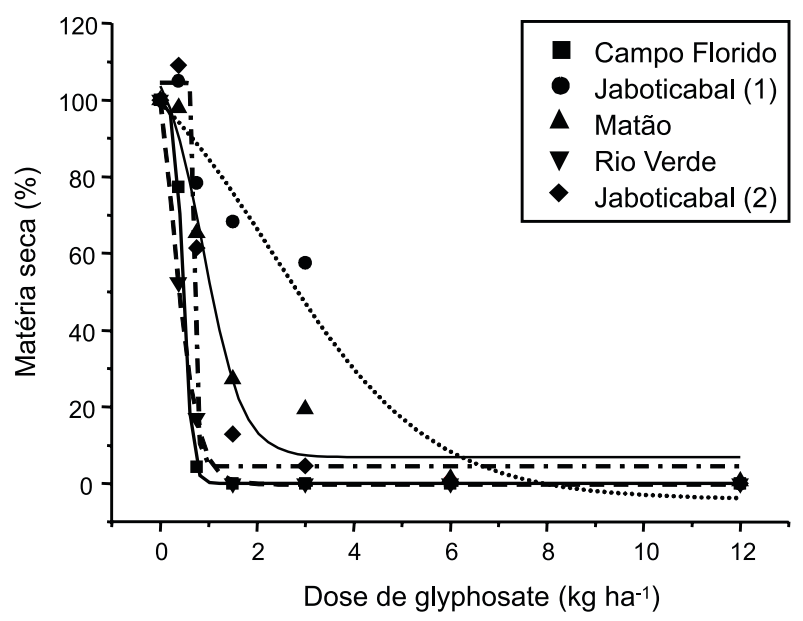

Figura 3 - Matéria seca da parte aérea (\%) de cinco populações de capim-amargoso (Digitaria insularis) aos 56 dias após a aplicação (DAA) de diferentes doses de glyphosate. Jaboticabal (1): área de produção de grãos; e Jaboticabal (2): área não agrícola. Jaboticabal-SP. 2008/2009.

Tabela 3 - Parâmetros das equações ${ }^{1 /}$ que descrevem o controle de cinco populações de capim-amargoso (Digitaria insularis) com diferentes doses de glyphosate, além das doses que obtiveram $50 \%$ de controle $\left(\mathrm{C}_{50}\right)$ ou de redução de matéria seca $\left(\mathrm{GR}_{50}\right)$. Jaboticabal-SP. 2008/2009

\begin{tabular}{|c|c|c|c|c|c|}
\hline \multirow{2}{*}{ Variável } & \multirow{2}{*}{ População } & \multicolumn{3}{|c|}{ Parâmetro } & \multirow{2}{*}{$\mathrm{C}_{50}$ ou $\mathrm{GR}_{50}$} \\
\hline & & $A_{2}$ & $A_{1}$ & $d x$ & \\
\hline \multirow{5}{*}{ Controle aos $28 \mathrm{DAA}$} & Campo Florido & 99,415 & $-0,046$ & 0,079 & 0,605 \\
\hline & Jaboticabal & 99,361 & 2,378 & 0,676 & 3,988 \\
\hline & Matão & 99,986 & $-36,231$ & 1,223 & 1,514 \\
\hline & Rio Verde & 99,900 & $-1,389$ & 0,134 & 0,572 \\
\hline & Área não agrícola & 97,749 & $-3,137$ & 0,190 & 0,895 \\
\hline \multirow{5}{*}{ Controle aos 56 DAA } & Campo Florido & 100,000 & $-1,341$ & 0,014 & 0,727 \\
\hline & Jaboticabal & 99,996 & $-0,115$ & 0,540 & 4,580 \\
\hline & Matão & 95,618 & $-23,230$ & 1,133 & 1,899 \\
\hline & Rio Verde & 100,000 & $-9,677$ & 0,015 & 0,737 \\
\hline & Área não agrícola & 94,418 & $-1,089$ & 0,211 & 1,183 \\
\hline \multirow{5}{*}{ Matéria seca aos 56 DAA } & Campo Florido & 100,402 & $-0,0002$ & 0,087 & 0,480 \\
\hline & Jaboticabal & 124,894 & $-4,170$ & 1,654 & 2,309 \\
\hline & Matão & 114,582 & 6,862 & 0,409 & 0,889 \\
\hline & Rio Verde & 136,390 & $-0,224$ & 0,254 & 0,257 \\
\hline & Área não agrícola & 104,519 & 4,489 & 0,021 & 0,756 \\
\hline
\end{tabular}

${ }^{1 /}$ Equação: $\mathrm{y}=A_{2}+\left(A_{1}-A_{2}\right) /\left(1+\exp \left(\left(x-\mathrm{C}_{50}\left(\mathrm{ou} \mathrm{GR}_{50}\right)\right) / d x\right)\right)$. 
Aos 56 DAA, o $\mathrm{C}_{50}$ foi de 0,$737 ; 0,727 ; 1,183$; 1,899; e 4,580 $\mathrm{kg} \mathrm{ha}^{-1}$ para as populações de Rio Verde, Campo Florido, Jaboticabal (2), Matão e Jaboticabal (1), respectivamente (Tabela 3). Esse fato evidencia que as populações de Jaboticabal (1), quando pulverizadas com glyphosate no estádio de desenvolvimento de sete a oito perfilhos e altura média de $40 \mathrm{~cm}$, são 6,26 vezes menos sensiveis ao herbicida do que os indivíduos de Campo Florido e Rio Verde.

Para matéria seca da parte aérea, as doses de glyphosate necessárias para promover redução de $50 \%\left(\mathrm{GR}_{50}\right)$ do acúmulo de massa foram de 0,257; 0,480; 0,756; 0,899; e 2,309 $\mathrm{kg} \mathrm{ha}^{-1}$ para os indivíduos de Rio Verde, Campo Florido, Jaboticabal (1), Matão e Jaboticabal (1), respectivamente (Tabela 3). Embora tenham sido verificadas diferenças expressivas na suscetibilidade e tolerância das populações de capim-amargoso ao herbicida glyphosate, não se pode inferir que os indivíduos menos sensíveis, como os de Jaboticabal (2) e Matão, sejam resistentes. Para confirmação de um novo caso de resistência, além da realização de experimentos de curva de dose-resposta, a caracterização da herdabilidade da resistência da planta daninha ao herbicida deve ser feita. Além disso, um único experimento de curva de dose-resposta não é suficiente para os casos com fator de resistência menor que 10. Esse fato exige a realização de experimentos de curva de dose-resposta em casa de vegetação e campo utilizando-se plantas suscetiveis e potencialmente resistentes, de tamanho e localização similares (Gazziero et al., 2008).

O fator de resistência é calculado pelo quociente entre o $\mathrm{C}_{50}$ ou $\mathrm{GR}_{50}$ do biótipo resistente e o $\mathrm{C}_{50}$ ou $\mathrm{GR}_{50}$ do biótipo suscetível. Nesta pesquisa, considerando as populações de Rio Verde e Campo Florido como suscetiveis, o fator de resistência é da ordem de 2,4 a 2,6 e de 6,3 a 6,8 para Matão e Jaboticabal (1), respectivamente. Portanto, os valores são inferiores a 10 , sendo necessária a realização de outros estudos para confirmação da resistência.

Mudanças relacionadas a absorção, translocação, sítio de ação, metabolização ou até mesmo compartimentalização do glyphosate pelas plantas de capim-amargoso podem explicar a variabilidade de resposta dos indivíduos à ação do produto. No trabalho sobre absorção e translocação de ${ }^{14} \mathrm{C}$-glyphosate em biótipos suscetiveis e resistentes de $C$. bonariensis, Ferreira et al. (2008) mencionaram que o mecanismo de resistência está relacionado à translocação diferencial desse herbicida nos biótipos, pois houve maior concentração do ${ }^{14} \mathrm{C}$-glyphosate absorvido nas folhas, no caule e nas raizes do biótipo suscetivel comparado ao biótipo resistente, que apresentou maior acúmulo apenas na folha tratada. Para Lolium rigidum e L. multiflorum, Preston et al. (2009) mencionaram que foram identificados dois mecanismos de resistência ao glyphosate: a alteração do sítio de ação devido à substituição na posição 106 da enzima EPSPS de prolina para treonina, alanina ou serina; e a translocação reduzida do herbicida das folhas para as raízes.

A diversidade genética das populações de $D$. insularis também deve ser levada em consideração. A variabilidade genética das populações de plantas daninhas é afetada por inúmeros fatores evolutivos, como o sistema de produção, a interação entre a cultura e a planta daninha (fluxo gênico através da dispersão do pólen e da semente), a distribuição geográfica e a seleção natural (Huangfu et al., 2009). Pesquisas sobre diversidade genética das plantas cultivadas têm sido desenvolvidas para espécies, variedades, cultivares e caracterização de biótipos, porém poucos estudos têm sido feitos com plantas daninhas (Rocha et al., 2009). O conhecimento se a diversidade genética da planta daninha é a mesma entre populações diferentes - especialmente entre aquelas sujeitas à seleção ocasionada pelo uso repetitivo de herbicidas e outra sem histórico de aplicação - é necessário (Huangfu et al., 2009).

Cícero et al. (2009) afirmaram que o emprego da técnica RAPD evidenciou a existência de diferenças genéticas entre 12 acessos de Pistia stratiotes, indicando variabilidade genética entre eles, sobretudo entre os de Itapura e Três Lagoas, discriminados em um grupo isolado dos demais. Quando pulverizados com glyphosate, os piores resultados de controle foram obtidos para os acessos de Curitiba e Cambaratiba. Esses autores concluíram que a variabilidade genética das populações de $P$. stratiotes não teve correspondência com a 
resposta de tolerância ou sensibilidade ao glyphosate.

O uso de modelagem em estudos de dinâmica populacional de plantas daninhas nos ambientes agrícolas permitirá simular a resposta da comunidade infestante submetida a condições altamente variáveis de crescimento (incluindo fatores climáticos e agronômicos) por um número de anos ou décadas. A esse respeito, Thornby \& Walker (2009) propuseram um modelo para simular a evolução de biótipos resistentes de Echinochloa colona em áreas agrícolas do norte da Austrália, o qual previu que a taxa de evolução da resistência ocorreria de 15 a 18 anos após a introdução e o uso intensivo de glyphosate. As simulações de validação indicaram que o modelo foi capaz de simular a evolução da resistência com razoável exatidão. No entanto, esses autores concluíram que serão necessários novos trabalhos de validação, usando os dados das populações resistentes de E. colona recentemente confirmados naquele país e os níveis de risco para uma série de práticas regionais relacionadas aos sistemas de cultivo e ao controle de planta daninha, incluindo estratégias preventivas para impedir o desenvolvimento de resistência ao glyphosate.

Quanto à análise comparativa dos tratamentos de interesse, a interação biótipos $\mathrm{x}$ herbicidas foi significativa $(p<0,01)$ para todas as variáveis avaliadas (Tabela 4). Os biótipos de Jaboticabal ( 1 e 2) e Matão foram altamente sensiveis à associação de glyphosate ao fluazifop, com mortalidade de $100 \%$ das plantas. Em outro estudo, Correia \& Durigan (2009) relataram que o herbicida quizalofop-p-tefuril isolado e associado ao glyphosate $(1,44 ; 2,16$; e $2,88 \mathrm{~kg} \mathrm{ha}^{-1}$ ), combinados à aplicação sequencial de $1,44 \mathrm{~kg} \mathrm{ha}^{-1}$ de glyphosate, resultaram no melhor controle de plantas adultas e perenizadas de capim-amargoso na área agrícola da Fazenda de Ensino, Pesquisa e Produção da UNESP, Jaboticabal-SP,

Tabela 4 - Porcentagem de controle de capim-amargoso (Digitaria insularis) aos 28 e 56 dias após a aplicação (DAA) de glyphosate associado aos herbicidas fluazifop-p-butil ou diuron + paraquat em plantas adultas de populações oriundas de cinco locais, além da matéria seca da parte aérea das plantas aos 56 DAA. Jaboticabal-SP. 2008/2009

\begin{tabular}{|c|c|c|c|c|c|c|}
\hline \multirow{3}{*}{ Herbicida } & \multirow{3}{*}{$\begin{array}{c}\text { Dose } \\
\left(\mathrm{kg} \mathrm{ha}^{-1}\right)\end{array}$} & \multicolumn{5}{|c|}{ Local das populações } \\
\hline & & $\begin{array}{l}\text { Campo } \\
\text { Florido }\end{array}$ & Jaboticabal & Matão & Rio Verde & $\begin{array}{l}\text { Área não } \\
\text { agrícola }^{1 /}\end{array}$ \\
\hline & & \multicolumn{5}{|c|}{ Controle (\%) - $28 \mathrm{DAA}$} \\
\hline Glyphosate & 0,0 & $0,00 \mathrm{~b}^{2 /}$ & $0,00 \mathrm{c}$ & $0,00 \mathrm{c}$ & $0,00 \mathrm{~b}$ & $0,00 \mathrm{~b}$ \\
\hline Glyphosate & 1,5 & $98,12 \mathrm{a}$ & $15,00 \mathrm{~b}$ & $47,50 \mathrm{~b}$ & $99,38 \mathrm{a}$ & $91,88 \mathrm{a}$ \\
\hline Glyphosate fluazifop-p-butil & $1,5+0,25$ & $98,75 \mathrm{a}$ & $97,50 \mathrm{a}$ & $99,38 \mathrm{a}$ & $97,50 \mathrm{a}$ & $96,88 \mathrm{a}$ \\
\hline Glyphosate diuron + paraquat $^{3 / /}$ & $1,5+(0,2+0,4)$ & $97,50 \mathrm{a}$ & $89,38 \mathrm{a}$ & $93,12 \mathrm{a}$ & $100,00 \mathrm{a}$ & $89,38 \mathrm{a}$ \\
\hline \multicolumn{2}{|c|}{ DMS (na coluna) } & \multicolumn{5}{|c|}{12,49} \\
\hline & & \multicolumn{5}{|c|}{ Controle (\%) - 56 DAA } \\
\hline Glyphosate & 0,0 & $0,00 \mathrm{~b}$ & $0,00 \mathrm{~b}$ & $0,00 \mathrm{c}$ & $0,00 \mathrm{~b}$ & $0,00 \mathrm{c}$ \\
\hline Glyphosate & 1,5 & $100,00 \mathrm{a}$ & $0,00 \mathrm{~b}$ & $32,50 \mathrm{~b}$ & $100,00 \mathrm{a}$ & $77,00 \mathrm{ab}$ \\
\hline Glyphosate fluazifop-p-butil & $1,5+0,25$ & $100,00 \mathrm{a}$ & $100,00 \mathrm{a}$ & $100,00 \mathrm{a}$ & $99,38 \mathrm{a}$ & $100,00 \mathrm{a}$ \\
\hline Glyphosate diuron + paraquat & $1,5+(0,2+0,4)$ & $96,88 \mathrm{a}$ & $78,12 \mathrm{a}$ & $87,50 \mathrm{a}$ & $100,00 \mathrm{a}$ & $71,25 \mathrm{~b}$ \\
\hline \multicolumn{2}{|c|}{ DMS (na coluna) } & & & 23,51 & & \\
\hline & & \multicolumn{5}{|c|}{ Matéria seca (g por vaso) } \\
\hline Glyphosate & 0,0 & $123,71 \mathrm{~b}$ & $124,50 \mathrm{c}$ & $131,47 \mathrm{c}$ & $154,15 \mathrm{~b}$ & $101,50 \mathrm{~b}$ \\
\hline Glyphosate & 1,5 & $0,00 \mathrm{a}$ & $84,18 \mathrm{~b}$ & $36,01 \mathrm{~b}$ & $0,00 \mathrm{a}$ & $12,57 \mathrm{a}$ \\
\hline $\begin{array}{l}\text { Glyphosate } \\
\text { Fluazifop-p-butil }\end{array}$ & $1,5+0,25$ & $0,00 \mathrm{a}$ & $0,00 \mathrm{a}$ & $0,00 \mathrm{a}$ & $0,00 \mathrm{a}$ & $0,00 \mathrm{a}$ \\
\hline Glyphosate diuron + paraquat & $1,5+(0,2+0,4)$ & $0,21 \mathrm{a}$ & $3,90 \mathrm{a}$ & $4,28 \mathrm{a}$ & $0,00 \mathrm{a}$ & $15,84 \mathrm{a}$ \\
\hline \multicolumn{2}{|c|}{ DMS (na coluna) } & \multicolumn{5}{|c|}{16,69} \\
\hline
\end{tabular}

1 Área sem histórico da aplicação de glyphosate. ${ }^{2 /}$ Com base no teste de Tukey a 5\% de probabilidade, médias seguidas de letra minúsculas, nas colunas, comparam os tratamentos de herbicidas dentro de cada local de coleta de sementes. ${ }^{3 /}$ Aplicação sequencial realizada 14 dias após a primeira. 
confirmando a sinergia dos herbicidas do grupo químico ariloxifenoxipropionato em mistura com o glyphosate no controle de populações tolerantes de capim-amargoso. A aplicação de glyphosate com sequencial de diuron + paraquat também foi eficaz no controle desses indivíduos; contudo, o efeito sinérgico observado foi menos acentuado do que para glyphosate + fluazifop.

Para as populações de Rio Verde e Campo Florido, a complementação de glyphosate com diuron + paraquat ou a sua associação com fluazifop não agregou vantagens, pois para esses indivíduos a aplicação única de $1,5 \mathrm{~kg} \mathrm{ha}^{-1}$ de glyphosate resultou em excelente controle das plantas. Procópio et al. (2006b) também verificaram que a adição dos herbicidas imazethapyr ( $\left.100 \mathrm{~g} \mathrm{ha}^{-1}\right)$ ou chlorimuron-ethyl (10 ou $20 \mathrm{~g} \mathrm{ha}^{-1}$ ) à calda de glyphosate $\left(1,62 \mathrm{~kg} \mathrm{ha}^{-1}\right)$ não aumentou o controle de populações de capim-amargoso em área agrícola do município de Rio Verde, GO, com resultados similares aos da aplicação de glyphosate $\left(1,62 \mathrm{~kg} \mathrm{ha}^{-1}\right)$ isolado. Segundo esses autores, o mesmo comportamento foi observado para a porcentagem de rebrota.

Com base nos resultados, pode-se concluir que as populações de capim-amargoso de Campo Florido e Rio Verde foram consideradas suscetiveis; as de Jaboticabal e Matão, tolerantes; e a da área não agrícola, de sensibilidade intermediária. A associação de glyphosate ao fluazifop ou a sua aplicação com sequencial de diuron + paraquat foram eficazes no controle das populações mais tolerantes de capimamargoso.

\section{LITERATURA CITADA}

CÍCERO, E. A. S. et al. Variabilidade genética e sensibilidade de acessos de Pistia stratiotes ao herbicida glyphosate. Planta Daninha, v. 25, n. 3, p. 579-587, 2007.

CHRISTOFFOLETI, P. J.; LÓPEZ-OVEJERO, R. F Resistência das plantas daninhas a herbicidas: definições, bases e situação no Brasil e no mundo. In: CHRISTOFFOLETI, P. J. (Coord.). Aspectos de resistência de plantas daninhas a herbicidas. 3.ed. Piracicaba: Associação Brasileira de Ação à Resistência de Plantas aos Herbicidas - HRAC-BR, 2008. p. 9-34.

CORREIA, N. M.; DURIGAN, J. C. Manejo químico de plantas adultas de Digitaria insularis com glyphosate isolado e em mistura com chlorimuron-ethyl ou quizalofop-p-tefuril em área de plantio direto. Bragantia, v. 68, n. 3, p. 689-697, 2009.
FERREIRA, E. A. et al. Glyphosate translocation in hairy fleabane (Conyza bonariensis) biotypes. Planta Daninha, v. 26, n. 3 , p. $637-643,2008$.

GAZZIERO, D. L. P. et al. Critérios para relatos oficiais estatísticos de biótipos de plantas daninhas resistentes a herbicidas. In: GAZZIERO, D. L. P.; GALLI, A. J. B.; KARAM, D. (Eds.). Sete Lagoas: Sociedade Brasileira da Ciência das Plantas Daninhas; Campinas: Associação Brasileira de Ação à Resistência de Plantas aos Herbicidas no Brasil, 2008. 22 p.

HUANGFU, C. H.; SONG, X. L.; QIANG S. ISSR variation within and among wild Brassica juncea populations: implication for herbicide resistance evolution. Genet. Res. Crop Evol., v. 56, n. 7, p. 913-924, 2009.

KISSMANN, K. G; GROTH, D. Plantas infestantes e nocivas. 2.ed. São Paulo: BASF, 1997. 825 p. (Tomo I)

LACERDA, A. L. S.; VICTÓRIA FILHO, R. Curvas doseresposta em espécies de plantas daninhas com o uso do herbicida glyphosate. Bragantia, v. 63, n. 1, p. 73-79, 2004.

LAMEGO, F. P.; VIDAL, R. A. Resistência ao glyphosate em biótipos de Conyza bonariensis e Conyza canadensis no Estado do Rio Grande do Sul, Brasil. Planta Daninha, v. 26, n. 2, p. 467-471, 2008.

MACHADO, A. F. L. et al. Análise do crescimento de Digitaria insularis. Planta Daninha, v. 24, n. 4, p. 641-647, 2006.

MACHADO, A. F. L. et al. Caracterização anatômica de folha, colmo e rizoma de Digitaria insularis.

Planta Daninha, v. 26, n. 1, p. 1-8, 2008.

NORSWORTHY, J. K. et al. Response of northeastern Arkansas palmer amaranth (Amaranthus palmeri) accessions to glyphosate. Weed Technol., v. 22, n. 3, p. 408-413, 2008.

PRESTON, A. C. et al. A decade of glyphosate-resistant Lolium around the world: mechanisms, genes, fitness, and agronomic management. Weed Sci., v. 57, n. 4, p. 435-441, 2009.

PROCÓPIO, S. O. et al. Efeitos de dessecantes no controle de plantas daninhas na cultura da soja. Planta Daninha, v. 24, n. 1, p. 193-197, 2006a

PROCÓPIO, S. O. et al. Eficácia de imazethapyr e chloriuron-ethyl em aplicações de pré-semeadura da cultura da soja. Planta Daninha, v. 24, n. 3, p. 467-473, 2006 b.

ROCHA, D. C. et al. Genetic variability among Commelina weed species from the states of Paraná and São Paulo, Brazil. Planta Daninha, v. 27, n. 3, p. 421-427, 2009.

SEEFELDT, S. S.; JENSEN, J. E.; FUERST, E. P. Log-logistic analysis of herbicide dose-response relationships.

Weed Technol., v. 9, n. 2, p. 218-225, 1995.

THORNBY, D. F.; WALKER, S. R. Simulating the evolution of glyphosate resistance in grains farming in northern Australia. Ann. Bot., v. 104, n. 4, p. 747-756, 2009. 